\title{
The use of melting curves as a novel approach for validation of real-time PCR instruments
}

\author{
Helmut Von Keyserling, Thomas Bergmann, Moritz Wiesel, and Andreas M. Kaufmann \\ Klinik für Gynäkologie, Charité-Universitätsmedizin Berlin, Campus Benjamin Franklin, Berlin, Germany
}

BioTechniques 51:179-184 (September 2011) doi 10.2144/000113735

Keywords: thermal cycler validation; high resolution melting analysis; qPCR; real-time PCR

Supplementary material for this article is available at www.BioTechniques.com/article/113735

Validation of PCR thermal cycler performance is crucial in order to obtain reliable results. In this study, high resolution melting curve (HRM) analysis is presented as a novel validation method for real-time PCR instruments. By applying HRM analysis using a defined PCR amplicon and EvaGreen dye, information about the temperature accuracy and thermal homogeneity of the heating block was obtained. This pilot study shows the potential of our technique for temperature validation of real-time quantitative PCR thermal cyclers. Our data correlated well with the temperature accuracy data obtained from the Mobile Temperature Acquisition System (MTAS; $r^{2}=0.93$ ), which conforms to the National Institute of Standards and Technology criteria, and our method was reproducible in independent runs $\left(r^{2}=0.95\right)$. The advantages of this HRM-based method include: (i) temperature measurement under real world conditions in the reaction liquid in closed reaction tubes; (ii) temperature measurement of all wells; and (iii) applicability to all real-time PCR instruments capable of HRM analysis.

Real-time PCR (1) is becoming more prevalent than conventional PCR and has become an essential technique in molecular biology (2). Much effort has been expended in improving real-time quantitative PCR (qPCR) assays and controls $(3,4)$. A common and unaccounted for source of error in qPCR data is the qPCR instrument itself. PCR instruments are subjected to vast and sudden changes in temperature that may lead to material fatigue caused by continuous cycles of expansion and contraction or by condensation. The accuracy of qPCR instruments is a crucial requirement for any assay to obtain reliable results. This concerns ramping rates and peak temperatures, but much more important is the homogeneity of temperature in all well positions in the qPCR instrument, especially when results from different wells are to be compared.

With qPCR becoming the method of choice for various diagnostic applications, qPCR instrument performance has been subjected to increased scrutiny by the scientific community. Discrepancies in temperature performance between different brands and types of thermal cyclers have been observed and shown to have a negative influence on PCR performance and results (5-7). Furthermore, the lack of proper methods to validate thermal cycler performance is a major factor limiting the widespread adoption of diagnostic qPCR by end users (8). Validation becomes particularly important when performing an assay using different thermal cycler models, since only validation will ensure proper and reproducible results (9).

The most common commercial validation methods are based on thermistor probes on printed circuit boards that have been developed for the validation of conventional PCR instruments. These usually consist of 15 thermistors that are positioned at predetermined locations in the heating block. For some of these, the lid has to be left open (e.g., Driftcon, Mobile Temperature Acquisition System [MTAS; CyclerTest, Landgraaf, The Netherlands]), while others fit into closed qPCR systems with drawers (e.g., Driftcon FFC). However, neither method takes into account the temperature crosstalk from the heated lid.

Other techniques have been suggested as alternatives to physical temperature sensors. For example, Gronlund et al. (10) have suggested the use of a system based on infrared (IR) thermography. IR thermography detects and visualizes IR energy radiating from the heating block (10). This method, however, also does not take into account the temperature crosstalk from the heating lid to the reaction wells, since the lid has to be left open. A major drawback of all these methods is that they directly measure the temperature of the block and not the sample. However, the temperature in the sample is important information (5).

Here, we describe a qPCR thermal cycler validation method that determines temperature in every well of the heating block using high resolution melting curve (HRM) analysis. This technique determines the melting point $\left(\mathrm{T}_{\mathrm{m}}\right)$ of doublestranded DNA by monitoring the loss of fluorescence from a DNA intercalating dye bound to the double-stranded DNA as it is melted into single-stranded DNA (see Supplementary Figure S1). A defined amplicon with a known $\mathrm{T}_{\mathrm{m}}$ is combined with the HRM-compatible dye EvaGreen and distributed into every well of a PCR plate. A melting curve analysis leads to $\mathrm{T}$ values for every well, which will be scattered 
around the reference $T_{m}$ depending on the performance of the heating block at every individual well position. $T_{m}$ values below this nominal temperature indicate that the well was too hot, while $T$ values above the nominal temperature indicate that the well was too cold. Our study demonstrates that HRM analysis can be applied as an alternative method to thermistor probes for the validation of qPCR instruments.

\section{Material and methods}

Preparation of the reference solution The reference solution consists of a buffer containing the 256-bp reference PCR fragment $\left(\mathrm{T}_{\mathrm{m}} \sim 90^{\circ} \mathrm{C}\right)$ and the intercalating, high resolution dye EvaGreen. The reference PCR fragment is derived from the Homo sapiens glutathione S-transferase theta 1 gene (GSTT1; NM_000853) and was amplified from human genomic DNA isolated from a cervical pap smear as follows: a single PCR was set up in $1 \times$ multiplex PCR master mix (Qiagen, Hilden, Germany) containing $1 \times$ EvaGreen dye (Jena Bioscience, Jena, Germany), $1 \mu \mathrm{L}$ human genomic DNA (10 ng), $300 \mathrm{nM}$ forward primer 5'-TTCCTTACTGGTCCTCACATCTC-3' (positions 522-545), and $300 \mathrm{nM}$ reverse primer 5'-TCACCG-
GATCATGGCCAGCA-3' (positions 758-777). The reaction was carried out in a total volume of $50 \mu \mathrm{L}$ using standard 200- $\mu$ L PCR tubes. The PCR was set up in a Chromo4 real-time PCR instrument (Bio-Rad Laboratories, Hercules, CA, USA) under the following conditions: initial denaturation at $95^{\circ} \mathrm{C}$ for $10 \mathrm{~min}$ followed by 40 cycles of denaturation at $95^{\circ} \mathrm{C}$ for $20 \mathrm{~s}$, annealing at $57^{\circ} \mathrm{C}$ for $20 \mathrm{~s}$, and elongation at $72^{\circ} \mathrm{C}$ for $45 \mathrm{~s}$. A melting curve analysis was carried out between $50^{\circ}$ and $95^{\circ} \mathrm{C}$ with a plate read every $0.1^{\circ} \mathrm{C}$ after holding the temperature for $5 \mathrm{~s}$. The resulting amplicon was used as template in an upscaled PCR: $2100 \mu \mathrm{L}$ PCR mixture were prepared in the same manner, containing $21 \mu \mathrm{L}$ template amplicon. After thorough homogenization, $43 \mu \mathrm{L}$ PCR mixture were distributed into each of 48 PCR tubes. A PCR without a melting curve analysis was carried out with the same temperature program as described above. After the PCR, the 48 tubes were pooled in a $10-\mathrm{mL}$ tube and vortex mixed thoroughly.

\section{HRM measurement}

Ten microliters of thoroughly homogenized reference solution were distributed into each well of 24 eight-well strips (white) and sealed with optical caps (Biozym Diagnostic, Hessisch Oldendorf, Germany). One strip-set, consisting of 12 eight-well strips, was placed into the Chromo4 real-time PCR instrument, and a melting curve analysis was carried out four times. Each time, the strips were turned around so that their positions were reversed on the heating block. The process was repeated with the second strip-set. Therefore, $2 \times 4 \times 96$ melting curves were obtained in total. The median $\mathrm{T}_{\mathrm{m}}$ value of all wells for each strip-set were set as the nominal $\mathrm{T}_{\mathrm{p}}$, representing the (zero) base-line in surface diagrams in Microsoft Excel.

\section{MTAS validation}

In this study, the MTAS was used as a reference method, since it is certified according to the U.S. National Institute for Standards and Technology (NIST). The instrument consists of 15 thermistor probes that are placed in the block prior to the analysis. A temperature program was run on a Chromo4 real-time PCR instrument. The probe-based system was set up with contact oil according to the manufacturer's instructions, and testing of the thermal unit was done without the lid covering the heating block. The test setup

\section{A NEW STANDARD IN RNA ISOLATION THE HIGHEST YIELD AND PURITY} RNAzol ${ }^{\circledR} T^{*}$ isolates total RNA, with mRNA and small RNA (200-10 bases) in separate fraction.

- The single-step method without phase separation

- No DNase treatment necessary

- RNA is ready for RT-PCR, microarrays and other applications

- No need for refrigerated centrifuge

- One reagent for solid and liquid samples
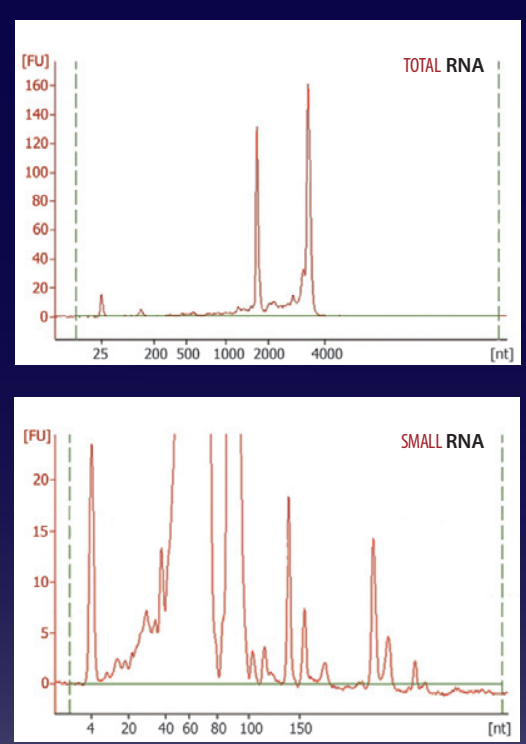
A

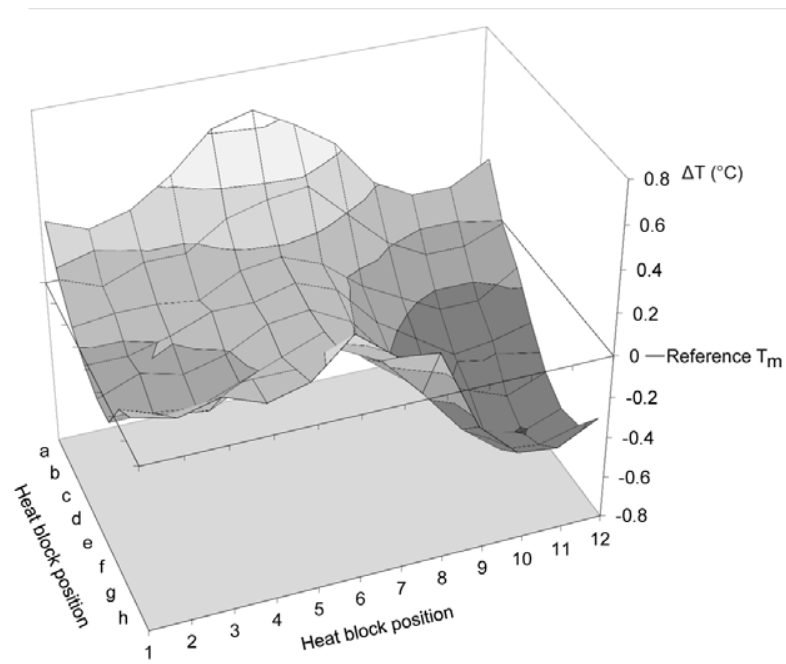

B

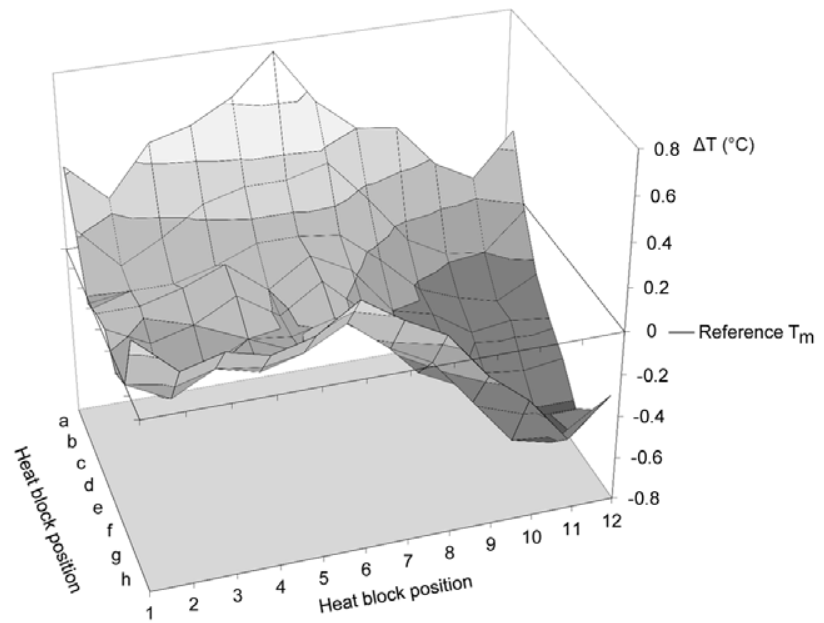

$\Delta \mathrm{T}\left({ }^{\circ} \mathrm{C}\right)$

$\square 0.6-0.8$

$\square 0.4-0.6$

$\square 0.2-0.4$

व0 0.2

$\square-0.2-0$

$\square-0.4--0.2$

口- $0.6--0.4$

$\square-0.8--0.6$

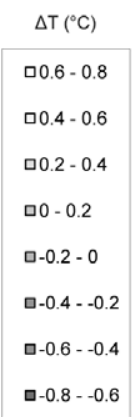

$0-0.8--0.6$
C

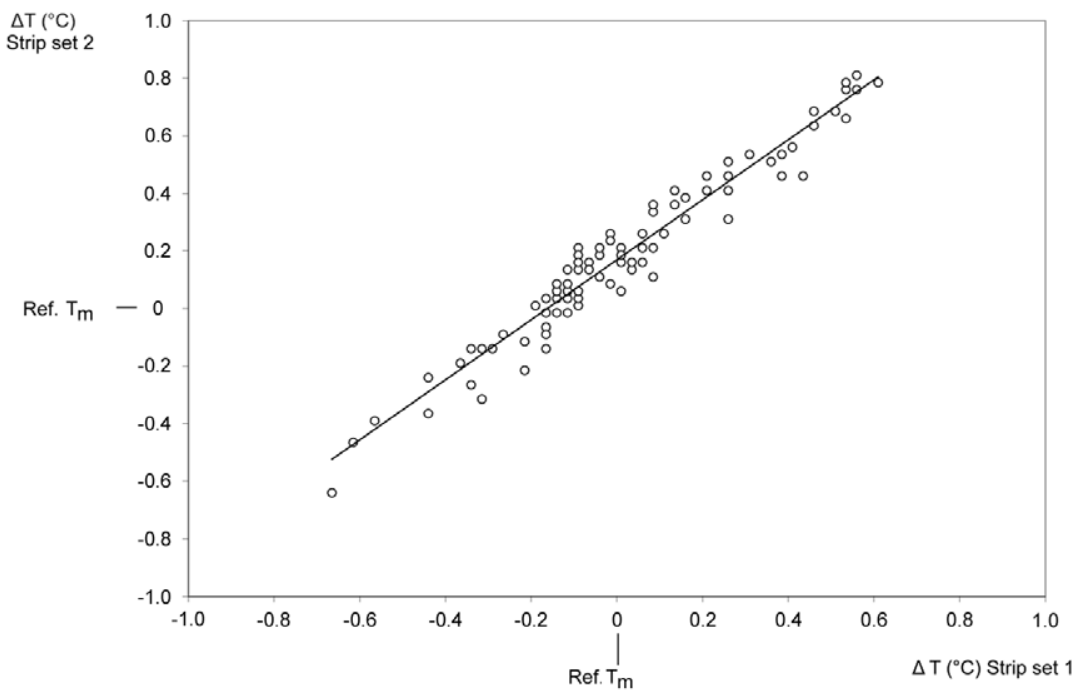

Figure 1. Temperature variation throughout the entire thermal block as measured by the HRM method. (A and B) Surface diagrams of the two 96-well strip-sets representing two independent validation runs. Breadth and depth represent the 96-well positions. The height represents the temperature variation around the median $T_{m}$, which is set to zero. (C) Correlation between the two independent validation runs as displayed in a scatter plot $\left(r^{2}=0.946\right)$.
NO ILLUSIONS JUST GENUINE 3D CELL CULTURE

\section{alvetex}

Alvetex ${ }^{\circledR}$ enables genuine 3D cell culture to be achieved simply and routinely.

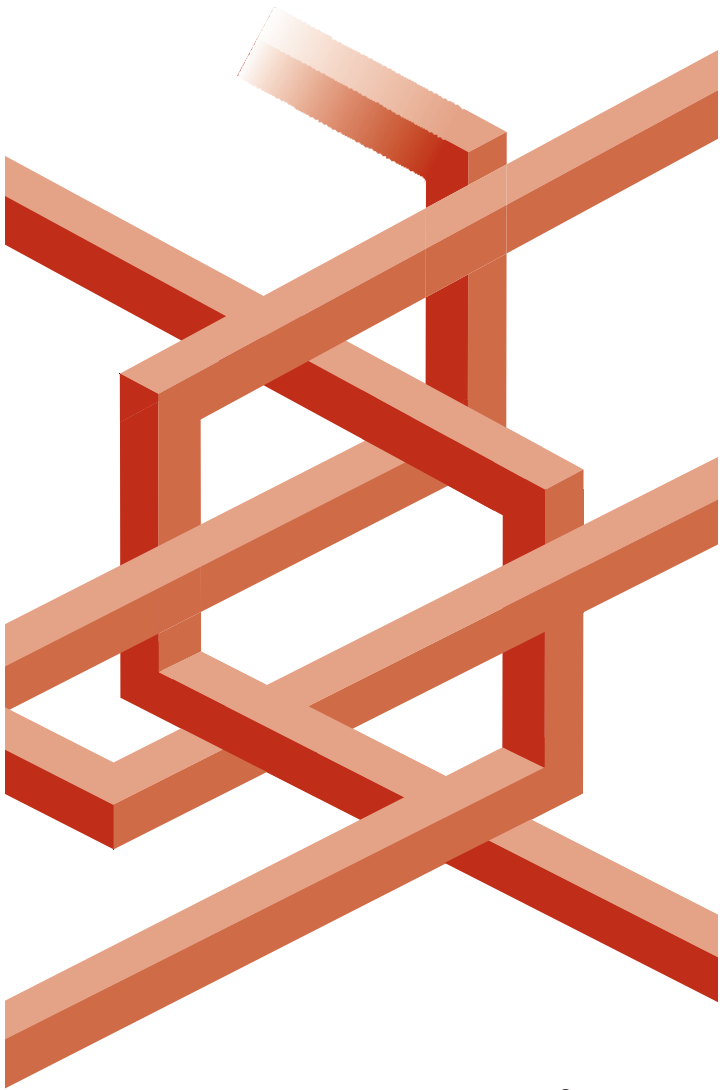

Reinnervate has developed alvete ${ }^{\circledR}$ to enable genuine 3D cell culture to be achieved routinely in the laboratory. It has been designed and developed with the specific needs of cell biologists in mind.

To find out more visit:

wWw.reinnervate.com

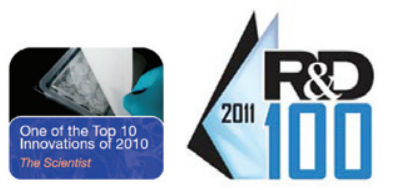


was; preheat protocol of $10.0^{\circ} \mathrm{C}$ for $60 \mathrm{~s}$, $100^{\circ} \mathrm{C}$ for $60 \mathrm{~s}, 10.0^{\circ} \mathrm{C}$ for $60 \mathrm{~s}$, followed by the standard temperature protocol of $30.0^{\circ} \mathrm{C}$ for $60 \mathrm{~s}, 95.0^{\circ} \mathrm{C}$ for $180 \mathrm{~s}, 30.0^{\circ} \mathrm{C}$ for $120 \mathrm{~s}, 90.0^{\circ} \mathrm{C}$ for $180 \mathrm{~s}, 50.0^{\circ} \mathrm{C}$ for $180 \mathrm{~s}, 70.0^{\circ} \mathrm{C}$ for $180 \mathrm{~s}, 60.0^{\circ} \mathrm{C}$ for $180 \mathrm{~s}$, $30.0^{\circ} \mathrm{C}$ for $60 \mathrm{~s}$. The 15 sensor positions on the heating block were: A1, A4, A7, A10, A13, D1, D8, D12, E4, E10, H1, H4, H7, $\mathrm{H} 10$, and $\mathrm{H} 15$.

\section{Results and discussion}

For the reference DNA fragment used in the melting curve analysis, we used an amplicon derived from the human GSTT1 gene that has a $\mathrm{T}_{\mathrm{m}}$ close to $90^{\circ} \mathrm{C}$ in the selected buffer. Since thermal homogeneity of the heating block decreases with increasing temperature, generally the block is more thermally homogeneous at lower as compared with higher temperatures. Although the temperature range between $50^{\circ}$ and $65^{\circ} \mathrm{C}$ is critical for primer annealing and PCR specificity, high temperatures during the melting steps affect DNA polymerases. This affects PCR efficiency, which in turn influences qPCR data dramatically.

However, a thermal block that performs well and is thermally homogenous at high temperature ranges will work even better and be more thermally homogenous at lower temperatures. This is why we have chosen an amplicon with a $\mathrm{T}_{\mathrm{m}}$ of $\sim 90^{\circ} \mathrm{C}$ and is also why the MTAS $^{\mathrm{m}}$ validation method for accuracy and homogeneity is based on measurement at $90^{\circ} \mathrm{C}$. With our reference amplicon that has a $\mathrm{T}_{\mathrm{m}}$ of

\section{Oligo 7 \\ Primer Analysis software}

Oligo has been re-designed from scratch. Several new features include:

O Fully automatic $P C R$ primers multiplexing, ๑ TaqMan \& nested primers search and analysis

O Search for siRNA and molecular beacon

including protein analysis data

$\Theta$ Batch processing and more!

For more information on the features and ordering the upgrade please check our web site.

oww oligo,net

or call us at

8007474362

A

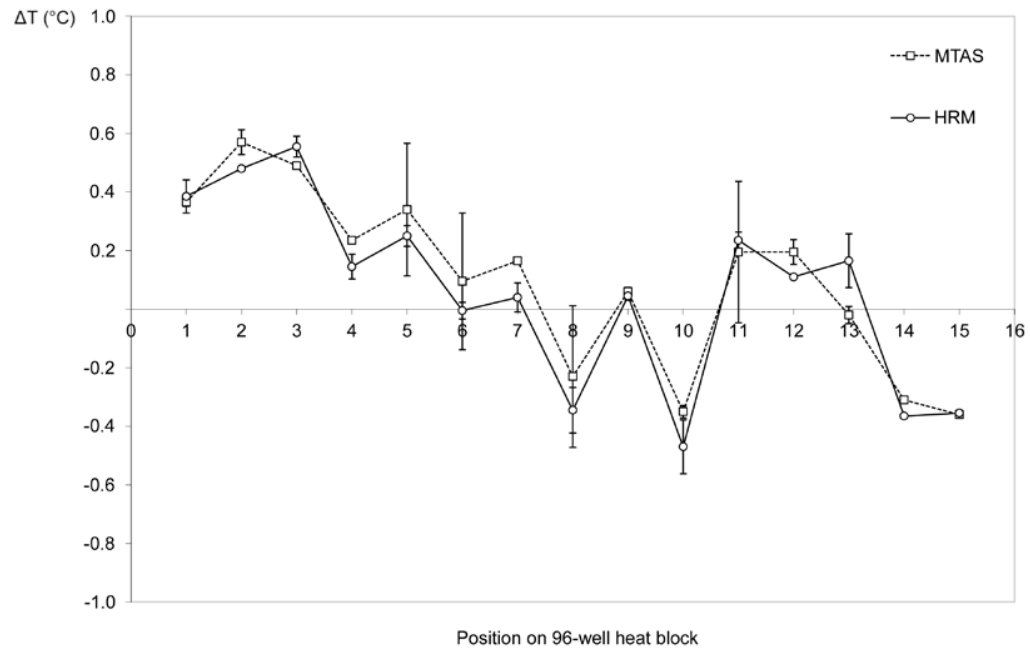

B

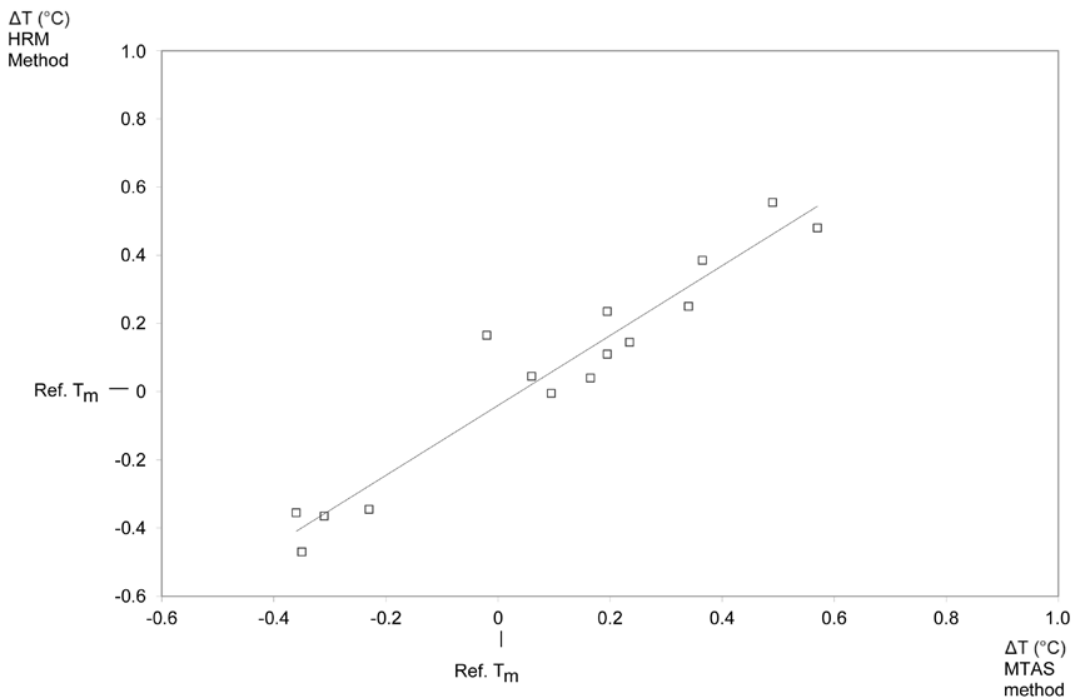

Figure 2. Direct comparison of MTAS with HRM point measurements. (A) Temperature differences of the 15 wells measured by MTAS compared with the corresponding wells measured by the HRM method. The 15 sensor positions on the 96-well heat block are: A1, A4, A7, A10, A13, D1, D8, D12, E4, E10, H1, $\mathrm{H} 4, \mathrm{H} 7, \mathrm{H1O}$, and $\mathrm{H} 15$. (B) Correlation of the MTAS method with the HRM-based method $\left(r^{2}=0.925\right)$ as displayed in a scatter plot.

$\sim 90.9^{\circ} \mathrm{C}$, the test conditions for these two methods are comparable.

To ensure the accuracy and reproducibility of our method, we thoroughly homogenized the reference solution consisting of the reference amplicon, EvaGreen I dye, and the appropriate buffer. Secondly, we measured each 96-well strip-set four times, turning the strips around each time. This was done in order to compensate for differences that may be caused by irregularities in the plastic of the eight-well strips. We tried to exclude all external factors that could influence the intrinsic melting curve in order to accurately determine the true temperature variations of the heating block.

As measured by our technique, the $\mathrm{T}_{\mathrm{m}} \mathrm{s}$ of the reference amplicon in the duplicate strip-sets were $90.83^{\circ} \mathrm{C}$ and $91^{\circ} \mathrm{C}$. These nominal $\mathrm{T}_{\mathrm{m}} \mathrm{s}$ were defined as the median $\mathrm{T}_{\mathrm{m}}$ of all data points for each strip set. The $\Delta \mathrm{T}$ above and below these $\mathrm{T}_{\mathrm{m}}$ for each strip set were calculated and displayed as block variations in surface diagrams (Figure $1 \mathrm{~A}$ and B). Each diagram represents a 96 strip-set that was measured four times. The hottest wells in both strip-sets were at position $\mathrm{A} 6\left(+0.66^{\circ}\right.$ and $+0.8^{\circ} \mathrm{C}$, respectively), and the coldest reaction well in the first strip-set was at position $\mathrm{F} 11\left(-0.61^{\circ} \mathrm{C}\right)$. In the second strip-set, the coldest position was at well G11 $\left(-0.65^{\circ} \mathrm{C}\right)$. The strip-set to strip-set correlation was $r^{2}=0.946$ (Figure 1C). To compare our method with a thermistor probe-based validation method, we used MTAS. In Figure 2A, we display the $\Delta \mathrm{T}$ of 15 well positions that were tested in 
the MTAS protocol together with the $\Delta \mathrm{T}$ of the corresponding positions determined by our melting curve method. To calculate the correlation coefficient between the two methods, these 15 positions are shown in a scatter plot (Figure 2B). This correlation between MTAS and the HRM-method was $r^{2}=0.925$.

It is clear that we have detected heating irregularities throughout the thermal block by our technique. Importantly, we have also measured absolute temperature values that correlated highly with the standard method MTAS.

The present work illustrates that it is important to measure all positions in the heating block during temperature validation. The MTAS validation, which only tests 15 wells of the block, revealed the hottest well at position $\mathrm{A} 4(+0.58$ after $120 \mathrm{~s})$ and the coldest at $\mathrm{H} 12$ (-0.37 after $120 \mathrm{~s})$, whereas our HRM method, which tests all wells, identified even hotter positions at A6 for both runs and even colder positions at F11/G11, which are wells that were not covered by the MTAS validation.

Due to its need for melting curve analysis by the fluorescence detection, our method is limited to the validation of qPCR instruAnother drawback is that our method cannot validate the ramp rates of the Chromo 4 due to limitations in this particular qPCR instrument that prevent rapid enough acquisition of fluorescence readout during rapid temperature ramping.

Here we demonstrate a fast and easy protocol that provides sensitive, reliable, and simultaneous detection of temperature deviations in all wells of the heating block in a qPCR instrument and can be applied to all thermal block formats and all qPCR instrument models. Using common qPCR reagents, this protocol allows temperature measurement under real world conditions. This method takes into account all effects, such as heat transfer between the heating block and the plastic tube, as well as the influence of the heating lid. the DNA fragment in the HRM analysis may be optimized in order to improve the accuracy of our qPCR cycler validation method. These factors include the length of the DNA fragment and its GC content and distribution, and the concentration of the DNA and ionic strength of the HRM reaction solution (11). Sequence errors introduced during PCR into the DNA fragment that might affect its $\mathrm{T}_{\mathrm{m}}$ could be avoided by using proofreading ration of water that could result in an altered ion strength can be prevented by better sealing of the wells. Although further optimization of our method is needed, we have shown that it can easily and rapidly detect problems in the temperature performance of a frequently used qPCR instrument. Thus, it provides a reliable troubleshooting tool that can determine if equivocal qPCR results are due to poor heating block performance without the need for additional instruments such as QTAS (Quanta Thermal Acquisition System; Quanta Biotech, Byfleet, UK), MTAS, or EaziVal (Anville Instrument Ltd, Farnham, UK).

\section{Acknowledgments}

We thank Andreas Dahl, Harald Seitz, and Achim Schneider for their support. H. K., T. B., and M. W. received an EXIST grant (03EGSBE129) from the German Federal Ministry of Economics and Technology in order to develop a thermal cycler validation kit for commercial use. ments and cannot be applied in conventional PCR machines.

However, certain factors that influence the melting point of Taq DNA polymerases or other amplification strategies. Evapo-

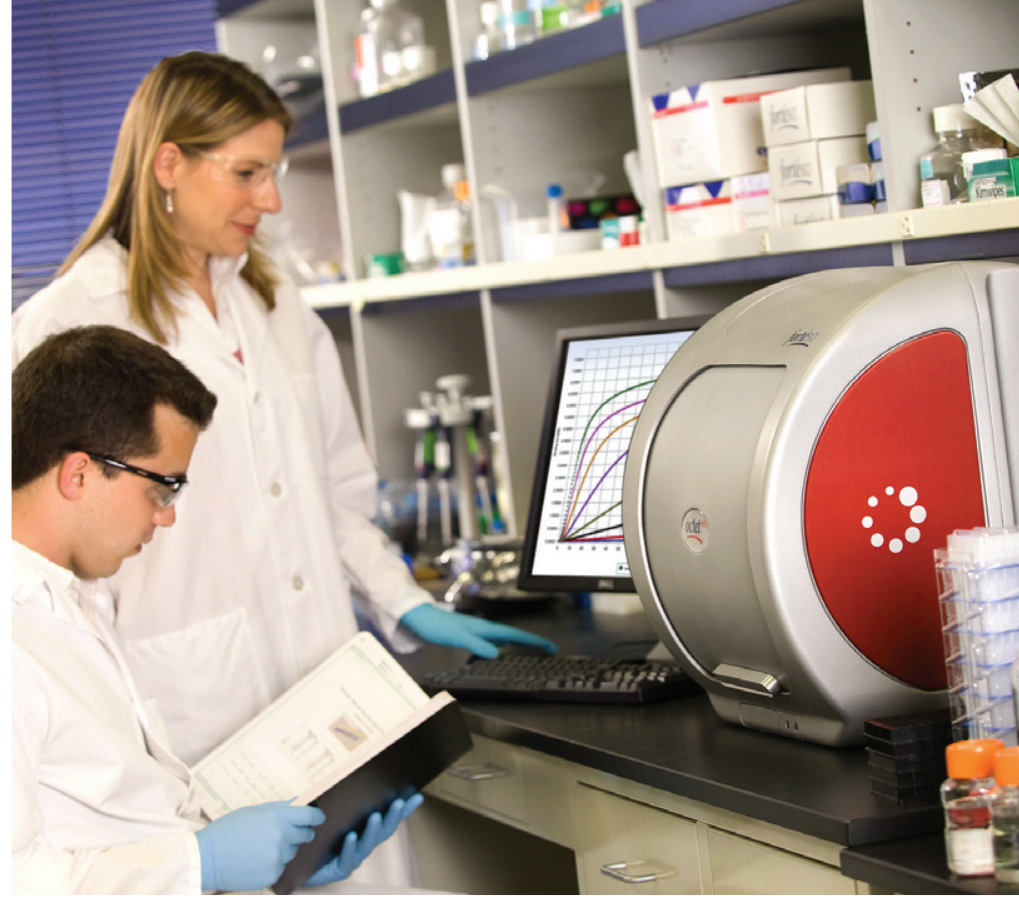

\section{Why Does Academia Prefer Octet ${ }^{\circ}$ For Label-Free Protein Characterization?}

\author{
The Octet RED system is a workhorse in our \\ lab that provides reliable small molecule- \\ protein binding kinetics and affinity data in a \\ fast, easy label-free assay.
}

James Delproposto, Research Associate, Life Sciences Institute, University of Michigan

\section{Out of the core lab, onto your benchtop} Measure concentration, kinetic and affinity constants and generate SPR-quality data right on your benchtop

\section{Label-free kinetic characterization in a few minutes!} Complete experiments in minutes rather than days using a Dip and Read ${ }^{\mathrm{m}}$ assay - setup requires only pipetting reagents into a 96- or 384-well microplate

\section{Direct quantitation assays for antibodies and other proteins}

Replace HPLC and ELISA with Octet to measure antibody and other protein concentrations in crude samples accurately without secondary reagents

Visit www.fortebio.com or call 888.0CTET-75 today to learn more about the Octet platform.

\section{fortéB।O}




\section{Competing interests}

H. K., T. B., and M. W. are pursuing commercialization of this technology.

\section{References}

1. Holland, P.M., R.D. Abramson, R. Watson, and D.H. Gelfand. 1991. Detection of specific polymerase chain reaction product by utilizing the $5^{\prime}----3^{\prime}$ exonuclease activity of Thermus aquaticus DNA polymerase. Proc. Natl. Acad. Sci. USA 88:7276-7280.

2. Ginzinger, D.G. 2002. Gene quantification using real-time quantitative PCR: an emerging technology hits the mainstream. Exp. Hematol. 30:503-512.

3. Stahlberg, A., M. Kubista, and M. Pfaffl. 2004. Comparison of reverse transcriptases in gene expression analysis. Clin. Chem. 50:1678-1680.

4. Bustin, S.A. and T. Nolan. 2004. Pitfalls of quantitative real-time reverse-transcription polymerase chain reaction. J. Biomol. Tech. 15:155-166.

5. Kim, Y.H., I. Yang, Y.S. Bae, and S.R. Park. 2008. Performance evaluation of thermal cyclers for PCR in a rapid cycling condition. BioTechniques 44:495-500.
6. Saunders, G.C., J. Dukes, H.C. Parkes, and J.H. Cornett. 2001. Interlaboratory study on thermal cycler performance in controlled PCR and random amplified polymorphic DNA analyses. Clin. Chem. 47:47-55.

7. Yang, I., Y.H. Kim, J.Y. Byun, and S.R. Park. 2005. Use of multiplex polymerase chain reactions to indicate the accuracy of the annealing temperature of thermal cycling. Anal. Biochem. 338:192-200.

8. Malorny, B., P.T. Tassios, P. Radstrom, N. Cook, M. Wagner, and J. Hoorfar. 2003. Standardization of diagnostic PCR for the detection of foodborne pathogens. Int. J. Food Microbiol. 83:39-48.

9. Schoder, D., A. Schmalwieser, G. Schauberger, J. Hoorfar, M. Kuhn, and M. Wagner. 2005. Novel approach for assessing performance of PCR cyclers used for diagnostic testing. J. Clin. Microbiol. 43:2724-2728.

10. Grønlund, H.A., C. Löfström, J.B. Helleskov, and J. Hoorfar. 2009. The use of infrared thermography as a novel approach for real-time validation of PCR thermal cyclers. Food Anal. Methods. 3:116-119.

11. Nakano, S., M. Fujimoto, H. Hara, and N. Sugimoto. 1999. Nucleic acid duplex stability: influence of base composition on cation effects. Nucleic Acids Res. 27:2957-2965.
Received 31 May 2011; accepted 11 August 2011.

Address correspondence to Andreas M. Kaufmann, Klinik für Gynäkologie, CharitéUniversitätsmedizin Berlin, Campus Benjamin Franklin, R. 4503, Hindenburgdamm 30, 12200 Berlin, Germany. e-mail: andreas.kaufmann@ charite.de

To purchase reprints of this article, contact: biotechniques@fosterprinting.com

\section{BIOHIT NEW FROM BIOHIT!}

\section{Innovating for Health}

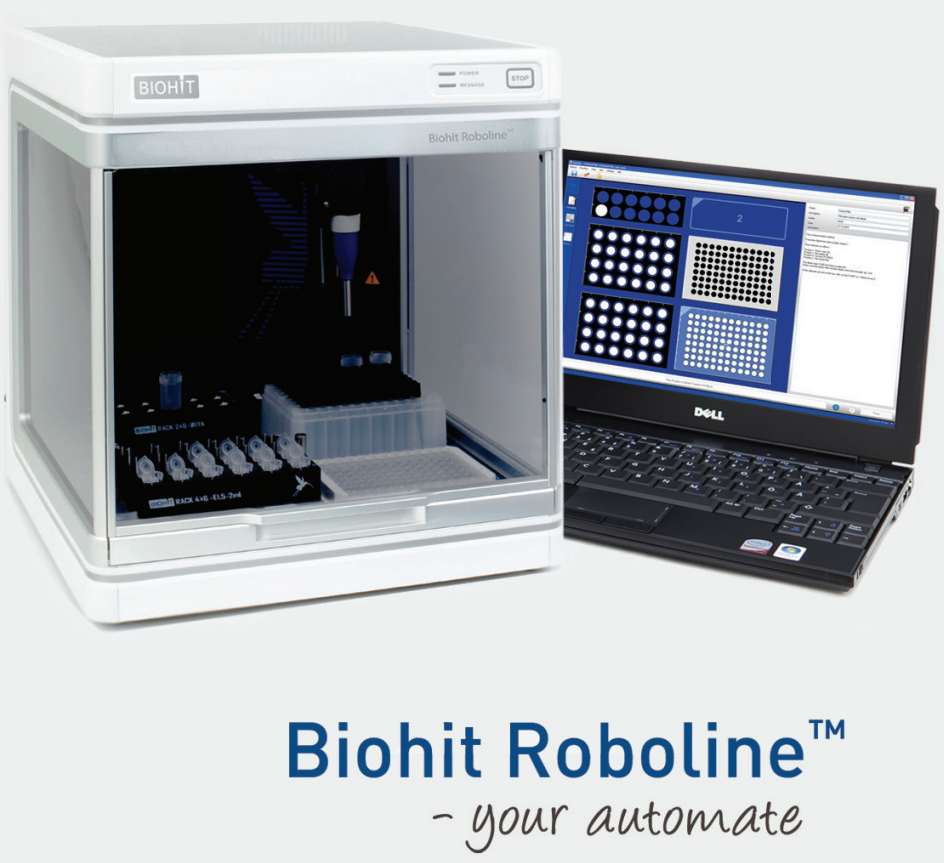

The Biohit Roboline is the ideal companion to automate your routine pipetting work. This small, quiet, and compact liquid handling automate is easy to place anywhere in the lab.

Roboline is the ideal companion to automate your pipetting:

- Precise pipetting minimizing human error

- Open programmability

- Saves time and increases efficiency

- Small footprint in the laboratory

- Quiet and compact

- Easy to use

Discover Roboline at http://www.biohit.com/us/roboline For all inquiries, please e-mail richard.miceli@biohit.com 